\title{
Investigation of the travel depth of the disc colter and the conditions for its balance
}

\author{
Vladislav Mishkhozhev, Aliy Gabaev*, Anatoly Nam, Vyacheslav Dzuganov, and Taymira \\ Pazova
}

Kabardino-Balkarian State Agricultural University named after V.M. Kokov, Lenin Avenue, 1V, 360030 Nalchik, Russia

\begin{abstract}
The seeding machine operation procedure consists of preparing the place where the seed should be placed, in placing the grain at a certain level below the soil surface in a certain order of arrangement and, finally, in the embedding - this work in large part falls on the share of the colter. The presented operation procedure of the seeder unit provides two main phases: reproduction of the maximum possible uniform feed of seed and its transporting to the colter; preparation of the groove, the required agrotechnical dimensions and distribution of seed material within it, followed by embedding them with soil. At the first phase of the seeding procedure, the issues of the outflow of seed material and its travel through the "seed tube - colter" system are relevant, and for the second phase, it is necessary to investigate the deformations of the soil layer reproduced by the colters, which is extremely necessary to select conditions that ensure uniform distribution of seed along the length and width of the row and at the desired depth. The article analyzes the investigation results by various authors devoted to the study of the stability of the depth of the opener stroke, its balance, and on their basis, analytical dependences are obtained.
\end{abstract}

\section{Introduction}

The vital task of agriculture is to guarantee the provision of our country with food, provided that soil fertility is preserved and increased, energy consumption is reduced, and the environment is protected. Its solution, especially at the stage of the formation of multistructured forms of management, is facilitated by the introduction of the latest technologies and machines, including the comprehensive mechanization of crop and livestock production on the basis of a scientifically grounded system of machines [1-6].

Each agricultural machine performs a certain technological process, which includes one or several technological operations, the implementation of which is accompanied by qualitative changes in the processed material.

Agricultural machines, unlike industrial ones, make direct contact with living forms: seeds, plants, soil with its various microorganisms, etc. Therefore, their successful application is due to the introduction of zoned varieties of agricultural crops, adapted to machine technologies.

${ }^{*}$ Corresponding author: alii gabaev@,bk.ru 
Agrotechnical requirements for the quality of technological operations have been developed for each agricultural machine.

It should be especially noted that each mechanized technological operation in the cultivation of agricultural crops should be optimized in terms of changeable application rates [7-11]. To do this, it is necessary for practical use to have a complete and suitable model of the relationship between such parameters as yield, amount of nutrients, moisture, density, soil fertility, field relief, and the like. Moreover, what is required is not a statistical fact, in what proportion are the mentioned parameters among themselves, namely, dynamic models of the relationship within a specific field, in other words we are talking about the need to develop a global model of agricultural production based on the laws of joint development of production and nature, modern systems theory, effective methods of substantiating decisions $[12,13]$.

Thus, as the main indicators of the work quality of the agricultural machines, in particular, grain seeders, in other words the output evaluation criteria of the technological process carried out by them, we can take such indicators as the uniformity of the distribution of seed and the uniformity of their embedding depth.

\section{Materials and methods}

Agrotechnical requirements for seeding of grain crops for embedding depths of 2-4, 4-5, 6$8 \mathrm{~cm}$ provide for permissible deviations: $\pm 0,5 ; \pm 0,7 ; \pm 1,0 \mathrm{~cm}$. Therefore, the colter shall provide the specified parameters of uniformity of seed embedding. Considering that soil shedding from the furrow walls has been reduced to a minimum, the fluctuation in the depth of the colters, which occurs as a result of external influences [14, 15], can be taken as the main factor in the unevenness of the seed embedding.

The disc colter system is represented by a drawbar, which is hinged at one end on a horizontal bar, and at the other end is rigidly mounted on the bolted casing with discs (Fig. 1). Thus, the colter system is a body that freely rotates about a horizontal axis parallel to the drawbar (with one degree of variance).

During the forward movement of the entire system, the following forces influence the colter:

- the weight $G$ that is applied to the center of gravity of the colter with a drawbar;

- pulling force $P$, the line of influence of which passes through the suspension point of the drawbar to the horizontal bar;

- soil drag $R$.

Since the colter does not have a base and rests on one point, the reaction of the support and the soil drag at this point are inseparable from each other. Taking into account the symmetrical shape of the colter relative to the longitudinal vertical plane (Fig. 2), it should be noted that the influence of resistance forces on the right and left causes one resultant $R$, located in the plane of symmetry of the disc colter [5]. 


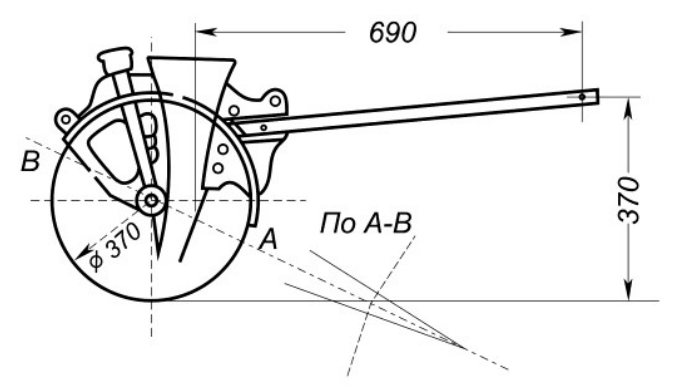

Fig. 1. Colter system with a drawbar.

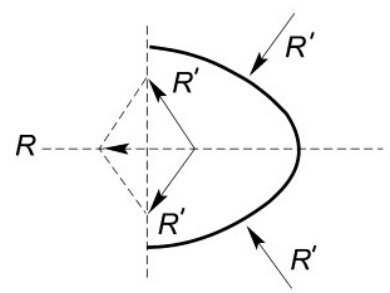

Fig. 2. Cross-section of the colter in the longitudinal vertical plane.

This conclusion is valid only when the colter operates in soil that is homogeneous in composition and condition. Otherwise, the emergence of one-sided impact is inevitable that is unbalanced on the other side.

Thus, when operating in a soil homogeneous in composition, due to the symmetrical shape of the disc colter, all three of the above forces $G, P$, and $R$ can be considered located in the same plane, and, therefore, reduced to one resultant.

With this indicator, the disc colter differs significantly from the working bodies of other tillage implements, for example, the plow blade, the shape of which is asymmetric and always determines the combined action of forces causing one resultant pair of forces.

\section{Results and discussion}

Considering the steady motion of the disc colter, in which the above forces should be in equilibrium, it is possible for this case to determine $R$ according to the given forces $P$ and $G$. Thus, in order to comply with the equilibrium condition, the following condition shall be met:

and, therefore,

$$
R+P+G=0
$$

$$
R=-(P+G)
$$

in other words, the resultant of the given forces $(P+G)$ shall be equal and oppositely directed to the force $R$ (Fig. 3). 


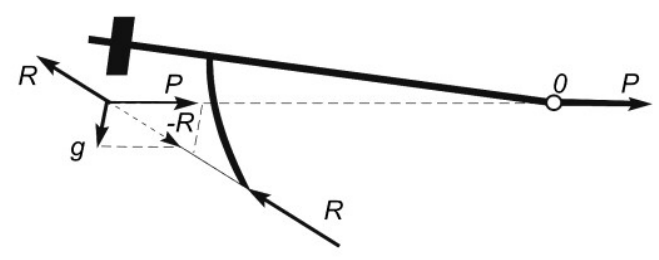

Fig. 3. Colter balance condition.

On the other hand, equation (2) can be represented in the following form:

$$
R=(-P)+(-G)
$$

that is, the force $R$, if it were known, can be decomposed into two components $(-P)$ and $(-G)$ so that the direction $P$ passes through the hinge $O$ of the suspension point. By transferring the force $(-P)$ to the hinge and decomposing it into two components: vertical $V$ and horizontal $H$, it can be noted that the force $V$ is transmitted through the hinge to the frame, and the force $H$ shall resist to forward movement [6].

Components $V$ and $H$ are associated with forces $R$ and $G$ the following ratios:

- for vertical projections:

- for horizontal projections:

$$
V=G-R \sin \alpha,
$$

$$
H=R \cos \alpha,
$$

- for a moment relative to the point $O$ :

$$
R r=G \ell,
$$

where $\alpha$-is a tilt of force $R$ to the horizontal plane; $r$ and $\ell-$ the shoulders of forces $R$ and $G$.

Of the equality (4) and (5) after the exception $\alpha$ the $R$ is determined:

$$
R=\sqrt{H^{2}+(G-V)^{2}} .
$$

After the exception $R$, the angle $\alpha$ of the force $R$ to the horizontal plane is determined:

$$
\operatorname{tg} \alpha=\frac{G-V}{H} .
$$

The location of the force $R$, taking into account equality (6), is determined by the shoulder:

$$
r=\frac{G \ell}{\sqrt{H^{2}+(G-V)^{2}}} .
$$

Thus, for the steady course of the disk colter, the force location value $R$ is determined by the values $G, H$ and $V$. Values $H$ and $V$ could be obtained using a special dynamometer, inserted into the hinge, where the drawbar of the colter is fastened.

In actual environment, in the during the operation, the force $R$ does not remain constant, as a result of which the colter either rises or falls, rotating relative to the suspension point at the fixing point to the cross bar.

The position of the suspension point of the colter has a significant effect on the values of the colter weight $G$ and shaft $P$ when balanced. It is easy to make sure that, changing the vertical position of the drawbar fixing point, different forces $G, P$ are required to balance the same resistance. 
If, for example, the force $R$ is balanced with the forces $P$ and $G$, when the suspension point is $O$ (Fig. 4). In this case $-R=P+G$, in other words resistance $-R$, equals in value $R$, but oppositely directed, is the resultant of forces $P$ and $G$, moreover, the force $P$ passes through the point $O$.

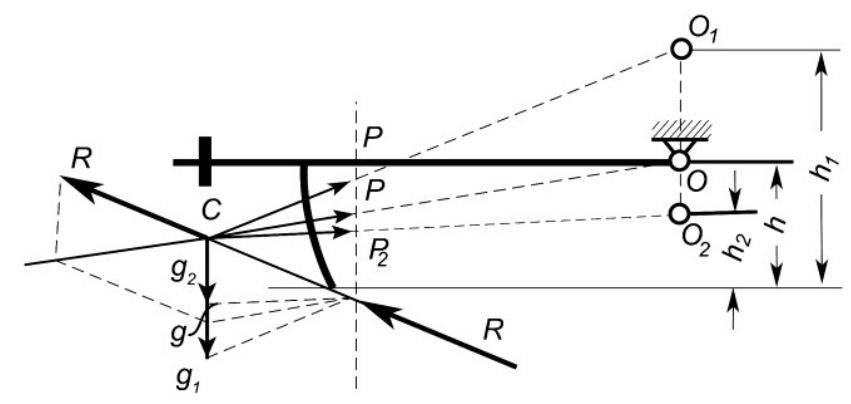

Fig. 4. Regulating of colter running depth

If we move the suspension point up the vertical $O_{1}$, then, obviously, the force $R$ shall be decomposed into two forces, a force $P_{1}$, which direction will be determined by a straight line $C O_{1}$, and a force $G_{1}$, having the same direction as the force $G$. Accordingly, with the rise of the suspension point in order to maintain balance, it is necessary to increase $P$ and $G$, conversely, decrease if the suspension point drops [7-8].

Leaving the suspension point of the colter at the same height, but moving it horizontally closer or further from the center of gravity of the colter, or, in other words, using short or long drawbars, different values $G$ and $P$ should be taken into account to balance the same resistance.

\section{Conclusions}

A short drawbar requires more colter weight and pulling force for balance, while a long drawbar requires less weight and less pulling force. The balance can be maintained with the same forces $P, G$ and $R$, if the suspension point is raised and at the same time moved further from the center of gravity of the disc colter, lengthening the drawbar accordingly. However, do not use very long drawbars to reduce the load on the colter. Equilibrium can be achieved with a relatively short drawbar out of unnecessary load, but for this you should take the suspension point of the colter below.

\section{References}

1. E. V. Kyul, A. K Apazhev, A. B. Kudzaev, N. A. Borisova, Indian Journal of Ecology, 44(2), 239-243 (2017)

2. A. Apazhev, V. Smelik, Y. Shekikhachev, L. Hazhmetov, Engineering for Rural Development, 18, 192-198 (2019)

3. A. K Apazhev, A. G. Fiaphev, Y. A. Shekikhachev, L. M. Hazhmetov, L. Z. Shekikhacheva, IOP Conference Series: Earth and Environmental Science, 315(5), 052023 (2019)

4. A. K Apazhev, Y. A. Shekikhachev, A. G. Fiapshev, L. M. Hazhmetov, E3S Web of Conferences / International Scientific and Technical Conference Smart Energy Systems (SES-2019), 124, 05054 (2019) 
5. V. V. Dzuganov, Y. A. Shekikhachev, A. Sh Teshev., M. M. Chechenov, V. Kh. Mishkhozhev, IOP Conf. Series: Materials Science and Engineering, 919(3), 032015 (2020)

6. A. K Apazhev, E. A. Polishchuk, Journal of Physics: Conference Series (JPCS), 1679, 042086 (2020)

7. A. L. Khazhmetova, A. K. Apazhev, Yu. A. Shekikhachev, L. M. Khazhmetov, A. G. Fiapshev, V. S. Kurasov, Polythematic network electronic scientific journal of the Kuban State Agrarian University, 153, 159-169 (2019)

8. H. H. Ashabokov, A. K. Apazhev, Yu. A. Shekikhachev, L. M. Khazhmetov, A. G. Fiapshev, AgroEcoInfo, 2(36), 32 (2019)

9. A. L. Khazhmetova, A. K. Apazhev, Yu. A. Shekikhachev, L. M. Khazhmetov, A. G. Fiapshev, AgroEcoInfo, 3(37), 37 (2019)

10. A. K. Apazhev, Yu. A. Shekikhachev, L. M. Khazhmetov, The Gorsky State Agricultural University news, 53(2), 138-143 (2016)

11. A. K. Apazhev, Yu. A. Shekikhachev, L. M. Khazhmetov, The Gorsky State Agricultural University news, 53(2), 146-151 (2016)

12. A. L. Khazhmetova, A. K. Apazhev, Yu. A. Shekikhachev, L. M. Khazhmetov, A. G. Fiapshev, Techniques and Equipment for countryside, 6(264), 23-28 (2019)

13. A. L. Khazhmetova, A. K. Apazhev, Yu. A. Shekikhachev, L. M. Khazhmetov, A. G. Fiapshev, AgroEcoInfo, 2(36), 29 (2019)

14. Y. A. Shekikhachev, V. H. Mishkhozhev, L. Z. Shekikhacheva, R. H. Zhigunov, Kan. V. Mishhozhev, Kaz. V. Mishhozhev, IOP Conference Series: Earth and Environmental Science, 548(2), 022004 (2020)

15. A. K. Apazhev, Yu. A. Shekikhachev, L. M. Khazhmetov, News of the Nizhnevolzhsky agrarian university complex: Science and higher professional education, 3(43), 238-245 (2016) 